\title{
A MATEMÁTICA NA EDUCAÇÃO INFANTIL
}

\author{
Camila da Silva Rondon Campos ${ }^{1}$ \\ Cleuza da Silva Freire ${ }^{2}$ \\ Irineide Santos Costa ${ }^{3}$ \\ Marta Maria Rodrigues de Miranda ${ }^{4}$ \\ Maria Carmelina Harbano ${ }^{5}$ \\ Rosidete Conceição da Silva Gaudêncio ${ }^{6}$ \\ Verônica Delgado do Nascimento Barbosa ${ }^{7}$
}

RESUMO: Durante o período da Educação Infantil, as crianças constroem suas bases de conhecimento matemático, embora seja importante para o desenvolvimento do raciocínio lógico, da criatividade e da estimulação cognitiva na Educação Infantil. Muitos professores ainda não percebem essa importância e acabam desenvolvendo conhecimentos matemáticos de forma incompleta, o que os torna um vilão ao longo de sua vida escolar. Este trabalho tem como objetivo compreender a abordagem matemática da educação infantil e a importância desse ensino para o desenvolvimento da criança. A matemática tem sido deixada de lado para ser trabalha mais tarde, durante o ensino fundamental, e muitas vezes pode levar a dificuldades ao longo da vida escolar da criança, contribuindo para dificuldades de aprendizagem, construir uma base sólida de conceitos matemáticos são importantes para serem explorados e implementados de forma adequada. divertido, tornando essa construção de conhecimento significativa para os alunos, além de mostrar que o professor tem importante papel nesse processo de mediação nesta construção.

Palavras-chave: Conhecimento Matemático. Educação Infantil. Desenvolvimento. Lúdico.

\footnotetext{
I Graduada em Pedagogia pela Universidade Federal de Mato Grosso - UFMT, Especialista em Educação Infantil pelas Faculdades Integradas de Várzea Grande - FIAVEC.

${ }^{2}$ Graduada em Pedagogia - Educação Infantil pela Universidade Federal de Mato Grosso, Especialista em Docência na Educação Infantil pela Universidade Federal de Mato Grosso - UFMT.

3 Graduada em Pedagogia pela Faculdade UNIVEST de Educação, Especialista em Educação Infantil e Letramento pela Faculdade UNIVEST de Educação.

${ }_{4}$ Graduada Pedagogia pela Universidade Paulista - UNIP, Especialista em Educação Especial e Educação Inclusiva pela Universidade Internacional - UNINTER.

${ }_{5}$ Graduada em Pedagogia pela Universidade Luterana do Brasil - ULBRA, Especialista em Educação Infantil com Ênfase na Educação Especial pela Faculdade Luso Capixaba.

${ }^{6}$ Graduada em Pedagogia pelo Centro Universitário Cândido Rondon - UNIRONDON, Especialista em Docência na Educação Infantil pela Universidade Federal de Mato Grosso - UFMT, Especialista em Relações Raciais no Contexto do EJA - Educação de Jovens e Adultos pela Universidade Federal de Mato Grosso UFMT, Especialista em Informática na Educação.

7 Graduada em Pedagogia pelo Centro Universitário Cândido Rondon - UNIRODON, Especialista em Educação Infantil na Faculdades Integradas de Várzea Grande - FIAVEC.
} 
ABSTRACT: During the period of Kindergarten, children build their bases of mathematical knowledge, although it is important for the development of logical reasoning, creativity and cognitive stimulation in Kindergarten. Many teachers still do not realize this importance and end up developing mathematical knowledge in an incomplete way, which makes them a villain throughout their school life. This work aims to understand the mathematical approach to early childhood education and the importance of this teaching for child development. Mathematics has been set aside to be works later, during elementary school, and can often lead to difficulties throughout a child's school life, contributing to learning difficulties, building a solid foundation of mathematical concepts are important to be properly explored and implemented. fun, making this construction of knowledge significant for students, in addition to showing that the teacher has an important role in this process of mediation in this construction.

Keywords: Mathematical Knowledge. Child education. Development. Ludic.

\section{INTRODUÇÃO}

Este artigo intitula-se Matemática na Educação Infantil tem como objetivo destacar a importância do ensino da Matemática nessa etapa do ensino e reconhecer sua importância para o desenvolvimento infantil.

A matemática é uma área que precisa ser explorada desde a Educação Infantil, mas como auxiliar de professora percebo que poucos educadores conhecem e percebem a importância de desenvolver a área da educação infantil. .

Quando não é bem desenvolvida, a matemática pode tornar-se um obstáculo ao longo da vida de uma criança, fazendo por exemplo com que muitas pessoas cresçam e se tornem adultas que não gostam de qualquer assunto que esteja ligado a matemático, tendo dificuldade em tudo na vida relacionado a esse conhecimento. Todo educador deve saber a importância da matemática na Educação Infantil para o desenvolvimento das crianças, a fim de melhor desenvolver aulas significativas para as mesmas.

A matemática quando desenvolvida de forma adequada, como aponta a Base Nacional Comum Curricular (BNCC), desde a Educação Infantil auxilia não somente no desenvolvimento escolar da criança, mas também no desenvolvimento como ser humano. A matemática tem uma importância fundamental para o desenvolvimento integral das 
capacidades e habilidades do ser humano, na Educação Infantil ela auxilia no desenvolvimento do raciocínio lógico e na capacidade de criação.

Ao pensarmos matematicamente sobre um problema estamos desenvolvendo as habilidades de unir, separar, subtrair, corresponder. E quando usados essas ferramentas na Educação Infantil, a criança passa a construir conhecimentos matemáticos, que auxiliam na ampliação das capacidades perceptivas e motoras que são necessárias para o seu desenvolvimento.

Um dos princípios de Piaget (1976) é que ensinar matemática na Educação Infantil vai muito além de ensinar a contar.

Os fundamentos para o desenvolvimento matemático das crianças estabelecem-se nos primeiros anos. A aprendizagem matemática constrói-se através da curiosidade e do entusiasmo das crianças e cresce naturalmente a partir das suas experiências [...]. A vivência de experiências matemáticas adequadas desafia as crianças a explorarem ideias relacionadas com padrões, formas, número e espaço duma forma cada vez mais sofisticada (PIAGET, 1976, p.73).

É na Educação Infantil que é instigada na criança o alargamento do pensamento lógico, por meio das atividades diversificadas que são apresentadas e construídas pelas possibilidades de flexibilidade, curiosidade e descoberta. O objetivo deste artigo é analisar o estudo da matemática na Educação Infantil a fim de compreender a importância desse ensino para o desenvolvimento da criança.

\section{DESENVOLVIMENTO 2.I A Educação Infantil}

A Educação Infantil, como primeira etapa da educação básica, ganha relevância a partir da Lei de Diretrizes e Bases da Educação Nacional (LDB) em especial no Referencial Curricular Nacional da Educação Infantil (RCNEI) quando aponta que deve-se garantir experiências em contextos significativos que explorem relações quantitativas, medidas, formas e orientações espaciotemporais e ultimamente, maior importância na Base Nacional Curricular Comum (BNCC).

Aprende-se e ensina-se por meio de experiências e nas relações que se estabelecem na escola. E isso se dá de forma planejada e não algo que acontece de qualquer jeito (SALLES; FARIA, 2012). 
Essas experiências vivenciadas devem ser planejadas de forma consciente pelos professores, uma vez que, a escola e o professor devem se comprometer com aquilo que fazem e acima de tudo precisam refletir sobre seu fazer de modo a tornarem-se conscientes daquilo que estão propondo.

Nesse sentido a matemática deve ser cada vez mais trabalhada e explorada na educação infantil, uma vez que o contar: sejam os alunos presentes em sala de aula, a quantidade de materiais a ser distribuído, a construção da agenda ou do calendário são instrumentos presentes no dia a dia dessa etapa, o que dá significado ao conhecimento matemático nesta fase.

A matemática está presente tanto no cotidiano da criança, quanto nas experiências oferecidas dentro da escola em suas diferentes situações. Seja nas relações quantitativas, nas grandezas, medidas, formas ou relações espaço-temporais.

Outros conceitos matemáticos são importantes de serem explorados na educação infantil como ordem, classificação, inclusão hierárquica até a construção do número. Para isso é preciso uma ação intencional e planejada do professor visando promover intervenções adequadas visando promover um ambiente matemático em que as aprendizagens se deem de forma contextualizada e significativa para as crianças.

Nesse aspecto o ensino da matemática na educação infantil deve ter por objetivo a apropriação dos diferentes usos e funções sociais do número, apropriação da linguagem matemática, a construção de formas convencionais ou não dos registros, entre outros.

Assim as aprendizagens devem proporcionar experiências e situações de exploração e manipulação de objetos comparando-os, sequenciando ou ordenando-os. Também devem contá-los, quantificá-los, numerá-los e fazendo estimativas. Usar a contagem em diferentes situações registrando, por exemplo, o resultado dos jogos e brincadeiras, assim como participar de jogos de faz de conta envolvendo a compra e venda, dentre outras tantas experiências propícias ao aprendizado da matemática.

Neste contexto o papel do professor ganha sentido e relevância uma vez que, passa a observar a criança, encorajá-la a pensar e refletir sobre os diferentes conceitos matemáticos, seja desafiando-as a pensar sobre suas hipóteses, propondo jogos ou criando um ambiente de aprendizagem significativa para a matemática. 


\subsection{Matemática na Educação Infantil}

A matemática está presente diariamente em nosso cotidiano e com a criança não poderia ser diferente, por exemplo, enquanto a criança brinca ela usa a matemática para medir distância, para diferenciar o pesado do leve, ela desenvolve conceitos espaciais como cima e embaixo, fora e dentro, frente e atrás, etc.

Ela deve ser ensinada às crianças como um meio de interpretação das coisas que nos rodeiam diariamente, assim formando pessoas conscientes para a cidadania e a criatividade e não somente como memorização. Existem diversas maneiras de trabalhar a matemática na Educação Infantil, pois ela está presente na arte, na música, em histórias na forma de como organizamos o pensamento, nas brincadeiras e nos jogos.

O professor não deve esquecer que a criança é um ser em formação e deve sempre cuidar para que essa formação seja sempre natural e com mais possibilidades possíveis para a criança.

$\mathrm{Na}$ Educação Infantil, o trabalho com noções matemáticas deve atender, por um lado, às necessidades da própria criança de construir conhecimentos que incidam nos mais variados domínios do pensamento e, por outro, precisa corresponder a uma necessidade social de melhor instrumentalizá-la para viver, participar e compreender um mundo que exige diferentes conhecimentos e habilidades (VIRGULINO, 2014, p. 78).

O professor deve sempre trabalhar como mediador do conhecimento, buscando sempre questionar, desafiar e promover situações incentivando os alunos a criarem sua própria autonomia, devendo sempre lembrar que cada criança é diferente da outra e que cada uma tem seu tempo de aprendizagem assim a criança passa a descobrir de forma prazerosa um novo mundo, o mundo dos números e do raciocínio lógico.

O trabalho com a matemática na Educação Infantil é importante pois, assim a criança está trabalhando com algo que ela realmente irá usar fora da escola, algo com que ela vai conviver o resto da vida.

$\mathrm{Na}$ Educação Infantil é onde a criança desenvolve suas capacidades e habilidades cognitivas e trabalhar com a matemática nessa fase é importante pois, é quando a criança aprimora o raciocínio lógico e a criatividade. A criança depois que passa a pensar, matematicamente, amplia sua capacidade perceptiva e motora que são essenciais para o seu 
desenvolvimento pleno e integral. Ruiz (2002, p. 218), por sua vez, discute a necessidade mundana da Matemática à luz do cognitivismo piagetiano:

\begin{abstract}
O epistemólogo Jean Piaget identifica a matemática como uma espécie de interface entre o espírito humano e o mundo, sendo um instrumento-chave no intercâmbio entre sujeito e universo. Aprender matemática é adquirir ferramentas cognitivas para atuar sobre a realidade. Para ele, existe o caráter de continuidade entre as estruturas lógico-matemáticas espontâneas do pensamento infantil e os edifícios formais construídos pelos matemáticos (RUIZ, 2002, p.218).
\end{abstract}

Com base nessa perspectiva observamos que a matemática tem importância fundamental no desenvolvimento do ser humano de modo geral. Na Educação Infantil entendemos como uma possibilidade de instrumentar a criança não apenas para a vida, mas também para o aprimoramento do raciocínio lógico, da inventividade e da capacidade de criação.

Os conteúdos matemáticos devem ser trabalhos na educação infantil de modo onde a criança construa seus conceitos matemáticos de forma livre, por meio de brincadeiras, atividades lúdicas, onde a criança participe ativamente, assim despertando a sua curiosidade, a partir do seu modo de interpretar o mundo passando a valorizar as suas potencialidades.

Aprender matemática não é só aprender uma linguagem, é adquirir também modos de ação que possibilitem lidar com outros conhecimentos necessários à sua satisfação, às necessidades de natureza integrativas, com o objetivo de construção de solução de problemas tanto do indivíduo quanto do coletivo (MOURA, 2007, p. 62).

O objetivo de trabalhar a matemática com as crianças na Educação Infantil é de que seja ampliada as suas habilidades, aumentar sua capacidade de resolver problemas, desenvolvendo sua argumentação por meio de questionamentos sobre resultados, construindo assim a própria autonomia da criança.

A exploração matemática pode ser um bom caminho para favorecer o desenvolvimento intelectual, social e emocional da criança. Do ponto de vista do conteúdo matemático, a exploração matemática nada mais é do que a primeira aproximação das crianças, intencional e direcionada, ao mundo das formas e das quantidades (LORENZATO, 2008, p. I).

Considerando o fato de que as crianças utilizam a matemática diariamente contando a quantidade de brinquedos que possuem, mostrando a sua idade com os dedos, dividir o lanche com o colega, a matemática na Educação Infantil busca, portanto desenvolver um 
caráter integrador, proporcionando atividades que desenvolvem a autonomia da criança, explorando seus conhecimentos prévios e mantendo seu espírito divertido através de jogos e brincadeiras.

Um dos vários objetivos da matemática é de ensinar as pessoas a resolverem problemas, com as crianças essas situações-problemas são representadas pelos jogos. Trabalhar a matemática de forma lúdica na Educação Infantil faz com que as crianças sintam maior prazer em aprender, pois as brincadeiras e os jogos fazem com que eles se envolvam com a matemática de forma mais prazerosa para eles.

As crianças na Educação Infantil se dispersam muito facilmente pois, ainda estão desenvolvendo sua capacidade de atenção, as brincadeiras nesse caso auxiliam no ensino da matemática com os pequenos, pois as crianças se sentem atraídas pelas atividades que são voltadas para o seu mundo.

O jogo é um ótimo instrumento para se trabalhar a matemática com as crianças, porém o professor deve ter noção dos conteúdos e das habilidades que estão presentes nas brincadeiras e os jogos devem ser desenvolvidos com algum objetivo para ser apenas usado para o lazer da criança. Sendo assim os professores devem estar preparados para utilizar esse instrumento de ensino, fazendo com que as aulas se tornem produtivas.

A capacidade lúdica do professor é um processo que precisa ser pacientemente trabalhada. Ela não é imediatamente alcançada. $O$ professor que, não gostando de brincar, esforça-se por fazê-lo, normalmente assume postura artificial facilmente identificada pelos alunos (KISHIMOTO, 2000, p. 122).

A matemática trabalhada de forma lúdica auxilia numa boa aprendizagem para a criança, os jogos auxiliam na formação de atitude, como enfrentar desafios, buscar soluções, desenvolver críticas, criação de estratégias e da possibilidade de alterar as brincadeiras quando o resultado não for satisfatório.

É na Educação Infantil que a criança constrói os conhecimentos que construirão e serão lapidados ao longo de sua vida. A escola deve levar em consideração as aprendizagens já adquiridas pela criança ao longo de sua vida e deve usar isso como base para ampliar ainda mais o seu conhecimento. $\mathrm{Na}$ Educação Infantil a criança tem a possibilidade de construir a base de sua educação e nesse momento é essencial o aprendizado da matemática. 
A matemática ao contrário do que muitos pensam abrange muito mais do que apenas cálculos, ela é usada de forma informal diariamente na nossa vida, seja para compras no supermercado vendo a quantidade de coisas que precisamos ou até mesmo jogos que exijam o raciocínio logico e estratégias.

Cada dia está mais comum o ensino através do lúdico, o que antes era ensinado de forma muitas vezes que não fazia sentido para as crianças hoje está sendo ensinado por meio de jogos e brincadeiras educativas. Na Educação Infantil é através de jogos e brincadeiras que se estimula a criança a desenvolver seu interesse e atenção fazendo isso de modo significativo.

Utilizar o jogo na Educação Infantil significa transportar para o campo de ensinoaprendizagem condições para maximizar a construção do conhecimento, introduzindo as propriedades do lúdico, do prazer, da capacidade de iniciação e ação ativa e motivadora (RCNEI, 1998, p. 37).

O lúdico na educação pode favorecer muito na aprendizagem da criança, pois é através das brincadeiras que a criança desenvolve a sua socialização, memorização, noção de tempo e espaço, raciocínio lógico além dos aspectos afetivos e emocionais.

É de suma importância a Matemática ser trabalhada de modo adequada na educação infantil, esta etapa é a base para o desenvolvimento da criança, e através da matemática que a criança desenvolve diversas habilidades que ela levará no decorrer de sua vida. Deve ser levado em consideração também que, quando não desenvolvida de forma adequada a matemática pode prejudicar o desenvolvimento da criança fazendo com que ela se torne um jovem ou adulto que não goste dessa disciplina e tenha dificuldades no desenvolvimento de certas habilidades.

Lorenzato (2008, p. I) diz que que a matemática pode ser um bom caminho para favorecer o desenvolvimento intelectual, social e emocional da criança. Essa é uma fase em que a criança deve se divertir e brincar, mas deve se levar em consideração que é na Educação Infantil que a criança constrói os conhecimentos que levarão para sua vida escolar ao longo do ensino fundamental e médio. As brincadeiras devem sim ocorrer pois se adquiri muito conhecimento de forma lúdica, o qual favorece muito na aprendizagem da criança, pois é através das brincadeiras que a criança desenvolve a sua socialização, memorização, noção de tempo e espaço, raciocínio lógico além dos aspectos afetivos e emocionais. 
Kamii (1990) afirma que as brincadeiras infantis, quando bem orientadas, despertam o interesse das crianças, criando situações problemas partindo do dia a dia de cada uma, oportunizando a interação entre elas através de conflitos cognitivos. É de extrema importância a matemática ser trabalhada de forma adequada na educação infantil, já que esta etapa é a base para o desenvolvimento da criança e é através da matemática que a criança desenvolve diversas habilidades que ela levará para o decorrer de sua vida escolar.

Existem professoras não estão se dando conta que a matemática não é apenas trabalhar cálculos, mas sim que ela é usada diariamente em nossas vidas de forma informal e que na educação infantil ela tem grande importância pois é através dela que nessa fase que as crianças desenvolvem as habilidades cognitivas, é quando se aprimora o raciocínio lógico e a criatividade. A criança depois que passa a pensar matematicamente amplia sua capacidade perceptivas e motoras que são essenciais para o seu desenvolvimento pleno e integral.

As professoras ao desconsiderarem o fato de que a Educação Infantil é a base para a vida escolar das crianças e que se ela não trabalha aspectos matemáticos nessa faixa etária essas crianças crescerão muitas vezes sem essa base e poderão ter fracasso nessa área futuramente.

\section{CONCLUSÃO}

A Matemática tem grande importância para o desenvolvimento humano e deve ser trabalhada desde a Educação Infantil, pois é nesta etapa que a criança constrói a base de sua vida escolar. A matemática quando trabalhada de maneira adequada com as crianças não servirá apenas para vida escolar da criança, mas também para ser desenvolvimento como ser humano, a matemática auxilia no raciocínio logico, no desenvolvimento da sua criatividade, e na capacidade de criação.

É preciso considerar que a matemática não é apenas cálculos e sim que ela está presente diariamente em nossas vidas quase sempre de modo informal e na educação infantil é importante que ela seja trabalhada de forma lúdica, buscando sempre trazer prazer as crianças na hora da construção do seu conhecimento, os jogos, pois eles auxiliam na formação de atitude, como enfrentar desafios, buscar soluções, desenvolver críticas, criação 
de estratégias e da possibilidade de alterar as brincadeiras quando o resultado não for satisfatório.

É importante lembrar que o professor deve sempre trabalhar como agente do conhecimento e não apenas um reprodutor de conteúdos que não fazem sentido para seus alunos. Lamentavelmente, alguns professores da nossa atualidade ainda não conhecem ou não dão importância do conhecimento matemático na educação infantil, o que faz com que muitas crianças saiam dessa fase sem as noções básicas que deveriam ser desenvolvidas nessa faixa etária, e isso muitas vezes pode causar um grande dano na vida escolar da criança, fazendo com elas cresçam e se tornem jovens que muitas vezes não tem um desenvolvimento nessa área e assim, a matemática passa cada vez mais a ser temida e odiada por crianças, jovens e adultos, isso por conta de um professor que não considera importante se trabalhar a matemática na Educação Infantil.

Nesse sentido verifica-se que a Base Nacional Comum Curricular (BNCC) poderá ser um elemento favorável, que contribuirá para que essa área do conhecimento, por

meio do planejamento docente intencional e da exploração desse campo de experiência nessa faixa etária, contribuirá para o desenvolvimento de atividades que envolvam os conhecimentos matemáticos, através de atividades em que possam manipular objetos, observando, quantificando-os, ordenando-os, bem como comparando seus pesos, seus comprimentos e utilizando o registro por meio de números.

\section{REFERÊNCIAS}

FARIA, Vitória. Currículo na educação infantil. 2ª ed. São Paulo: Ática, 2012.

KAMII, C; DEVRIES, R. A Criança e o Número: implicações educacionais da teoria de Piaget para a atuação junto a escolares de 4 a 6 anos. Campinas, Papirus, 1990.

KISHIMOTO, Tizuco Morchida. Jogo, brinquedo, brincadeiras e a educação. $4^{\text {a }}$ Ed. São Paulo, Editora Cortez: 2000.

LORENZATO, S. Educação Infantil e percepção matemática. Campinas: Autores Associados, 2008. MARCONI, Marina de Andrade; LAKATOS, Eva Maria. Técnicas de Pesquisa. $7^{\underline{a}}$ ed. São Paulo: Atlas, 2008. 
MOURA, M. Matemática na infância. In: MIGUEIS, M. R.; AZEVEDO, M. G. (org.). Educação Matemática na infância: abordagens e desafios. Vila Nova de Gaia. Gailivro, 2007.

PIAGET, J. Psicologia e Pedagogia. Rio de Janeiro. Forense Universitária, 1976.

RUIZ, Adriano Rodrigues. A matemática, os matemáticos, as crianças e alguns sonhos educacionais. Ciência \& Educação, v. 8, n. 2, p. 217-225, jun, 2002. Disponível em http://www.scielo.br/pdf/ciedu/v8n2/o6.pdf .Acesso em I4/II/202I.

SALLES, Fátima; FARIA, Vitória. Currículo na educação infantil. ª ed. São Paulo: Ática, 2012.

VIRGULINO, Carina Silvana. O ensino da matemática na educação infantil. 2014. Disponível em https://www.webartigos.com. Acesso em 14/11/2021. 